\title{
Intravenous Nicotine Reduces Cerebral Glucose Metabolism: A Preliminary Study
}

\author{
June M Stapleton ${ }^{1,4}$, Stephen F Gilson ${ }^{1,5}$, Dean F Wong'2, Victor L Villemagne ${ }^{1,6}$, Robert F Dannals ${ }^{2}$, Roger F \\ Grayson $^{3,7}$, Jack E Henningfield ${ }^{1,8}$ and Edythe D London*, I \\ 'Intramural Research Program, National Institute on Drug Abuse, National Institutes of Health, Baltimore, MD, USA; ${ }^{2}$ Department of Radiology, \\ Johns Hopkins University School of Medicine, Baltimore, MD, USA; ${ }^{3}$ Department of Anesthesiology, Johns Hopkins University School of Medicine, \\ Baltimore, MD, USA
}

\begin{abstract}
Nicotine is self-administered by smoking tobacco products, and enhances positive mood (at least in smokers). Since most drugs of abuse decrease regional cerebral metabolic rate(s) for glucose (rCMRglc) in human subjects, we posited that administration of nicotine would similarly reduce rCMRglc. Positron emission tomography (PET) with [F-I8]fluorodeoxyglucose was used to assess the effects of intravenous nicotine $(1.5 \mathrm{mg}$ ) on cerebral glucose metabolism in six healthy male volunteers (2I-38 years of age). Two PET assays (placebo and nicotine) were performed, and subjective self-reports of mood and feeling state were collected. Data were analyzed using analysis of variance. Nicotine reduced global glucose metabolism (by $9.51 \%$ of placebo control), with reductions in most of the 30 individual regions tested. Nine regions had bilateral effects that reached statistical significance $(p<0.05$, uncorrected for the number of regions tested), although the statistical model used did not separate these effects from a global effect. The subjects reported both positive and negative effects of nicotine on mood/feeling state. The widespread decreases in cerebral metabolism are consistent with the many effects of nicotine on cognition and mood. The findings indicate that nicotine resembles other drugs of abuse in reducing brain metabolism, perhaps by a common mechanism.

Neuropsychopharmacology (2003) 28, 765-772. doi: I0.1038/sj.npp. 1300106
\end{abstract}

Keywords: addiction; brain imaging; drug abuse; fluorodeoxyglucose; nicotine; positron emission tomography

\section{INTRODUCTION}

Nicotine interacts with binding sites on nicotinic acetylcholine receptors (nAChRs) to produce many behavioral and physiological effects, including influences on learning, memory, analgesia, anxiety, and convulsions (Lukas, 1998). Although the distributions of nAChRs in the mammalian brain have been studied by in vitro and ex vivo autoradiography (Clarke et al, 1984; London et al,

*Correspondence: Dr ED London, Department of Psychiatry and Biobehavioral Sciences, Neuropsychiatric Institute, University of California at Los Angeles, 760 Westwood Plaza, Box 60, Los Angeles, CA 90024, USA, Tel: +I 310825 0606, Fax: + 3108250812 , E-mail: elondon@mednet.ucla.edu

${ }^{4}$ Present address: Psychological Services, Arizona State Hospital, Phoenix, AZ 85007, USA

${ }^{5}$ Present address: Social Work Department, University of Maine, Orono, ME 04469, USA

${ }^{6}$ Present address: Department of Radiology, The Children's Hospital of Philadelphia, Philadelphia, PA 19104, USA

${ }^{7}$ Present address: Department of Anesthesiology, St. Joseph Medical Center, Baltimore, MD 20814, USA

${ }^{8}$ Present address: Pinney Associates, Bethesda, MD 208I4, USA

Received I I September 200 I; revised 4 September 2002; accepted 29 October 2002

Online publication: I November 2002 at http://www.acnp.org/ citations/Npp I 10102424 1985b), nicotine's effects in the brain extend beyond maps of cerebral nAChRs, and can be studied by measuring cerebral blood flow (CBF) or metabolism.

For example, in three smokers who abstained from smoking for 12 or more hours, smoking affected perfusion inconsistently, increasing relative $\mathrm{CBF}$ in the cerebellar hemispheres (all three subjects), frontal gyri (two of three), thalamus (one of three), and cingulate gyrus (one of three), as measured by $\mathrm{H}_{2}^{15} \mathrm{O}$ and positron emission tomography (PET) (Nagata et al, 1995). In another study $(n=18)$, intravenous nicotine increased normalized (relative to global) $\mathrm{CBF}$ in the pons and septum, and cigarette smoking increased normalized $\mathrm{CBF}$ in the prefrontal cortex, anterior cingulate gyrus, and putamen (Rose et al, 1998). In still another study of 18 smokers, deprived of smoking for $12 \mathrm{~h}$, nicotine increased normalized $\mathrm{CBF}$ in the right anterior thalamus, but decreased it in the left anterior temporal cortex and right amygdala (Zubieta $e t$ al, 2001).

Functional magnetic resonance imaging (fMRI), which uses an indirect measure of brain perfusion (ie the relative proportion of oxygenated and deoxygenated hemoglobin), has extended these findings. In 16 smokers, intravenous nicotine (cumulative dose $=4.5 \mathrm{mg} / 70 \mathrm{~kg}$ ) increased signal intensity in regions involved in arousal and reward (Stein et al, 1998). 
Few studies have tested the effects of nicotine or smoking on absolute measures of $\mathrm{CBF}$, and the findings have been inconsistent. In the aforementioned study of three abstinent smokers, PET with $\mathrm{H}_{2}^{15} \mathrm{O}$ indicated that smoking increased global CBF in one set of measurements but not in another test immediately afterward (Nagata et al, 1995). Another study showed that in four abstinent smokers, nicotine infusion did not affect global CBF, as measured with $\left[{ }^{133} \mathrm{Xe}\right]$, or cerebral oxygen uptake (Ghatan et al, 1998). In contrast, a PET study with $\mathrm{H}_{2}^{15} \mathrm{O}$ indicated that nicotine decreased global CBF in 10 subjects (Rose et al, 1998). Lastly, monitoring of middle cerebral artery flow by transcranial Doppler ultrasonography indicated that smoking a cigarette briefly accelerated CBF in each of 14 subjects tested (smokers and nonsmokers) (Boyajian and Otis, 2000).

The 2-deoxyglucose method, which infers function from the regional cerebral metabolic rate for glucose (rCMRglc) (Sokoloff et al, 1977), has been used extensively to assay pharmacological effects on regional brain function. It has been used to show that nicotine increases rCMRglc in rats, mostly in areas that have high densities of nAChRs (London et al, 1985a, 1988a; McNamara et al, 1990), such as thalamic nuclei. The cerebellar vermis also shows stimulation despite low densities of nAChRs (London et al, 1985a, b; Grünwald et al, 1987; McNamara et al, 1990). Nicotine increased extracellular dopamine while enhancing rCMRglc in the shell but not in the core of the nucleus accumbens (Pontieri et al, 1996), which has been implicated in the rewarding effects of abused drugs (London et al, 1996).

Extending this work to humans, using the $\left[{ }^{18} \mathrm{~F}\right]$ fluorodeoxyglucose (FDG) method and PET, the effects of nasal nicotine spray on cerebral glucose metabolism were compared to those of an active placebo (oleoresin of pepper) in 11 smokers who were abstinent overnight (Domino et al, 2000). The left inferior frontal and left posterior cingulate gyri, and the right thalamus showed relative metabolic increases due to nicotine, while the left insula and right occipital gyrus showed relative decrements. A nonsignificant decrease in global metabolic rate $(6.9 \%)$ was observed.

In the present study, the effects of intravenous nicotine $(1.5 \mathrm{mg})$ on cerebral glucose metabolism and self-reports of mood and feeling state were determined. The intravenous route of administration provides relative uniformity of dosing. Furthermore, prior work has shown that a $10-\mathrm{s}$ infusion of $1.5 \mathrm{mg}$ nicotine, as used in the present study, produces positive subjective self-reports (drug liking, high, stimulation) that are maximal during the first few minutes after nicotine administration and subside within $15 \mathrm{~min}$ (Jones et al, 1999), consistent with the rapidly spiking arterial plasma levels of nicotine observed after smoking (Henningfield et al, 1993) and with the brain uptake period following injection of FDG. We therefore selected this route of administration to characterize the distribution and nature of nicotine's effects on rCMRglc in humans.

Administration of euphorigenic drugs generally decreases rCMRglc (Stapleton and London, 1995; London et al, 1996). Abused drugs from different classes, including opiates, stimulants, benzodiazepines, and alcohol, manifest this phenomenon (London et al, 1996). Since nicotine resembles other drugs of abuse by enhancing positive mood, as measured by subjective self-reports (Henningfield et al,
1985; Soria et al, 1996; Jones et al, 1999), we hypothesized that nicotine would decrease rCMRglc, resembling the actions of other euphorigenic agents.

\section{MATERIALS AND METHODS}

Subjects were right-handed volunteers, 21-38 years of age, recruited through newspaper advertisements. They showed no pathological conditions in a complete physical examination and in standard diagnostic tests, including complete blood cell count, serum electrolyte assay, liver function tests, fasting blood glucose level, prothrombin and partial thromboplastin times, thyroid function tests, urinalysis, and electrocardiography. Patency of radial and ulnar arteries in both arms was demonstrated by Allen's test.

Potential research participants denied abuse of illicit drugs or alcohol, and were excluded if they reported any intravenous drug use. Past experimental use (but no regular or current use) of drugs by other routes was permitted ( $<10$ times). Use of alcohol (no more than three times per week or more than four drinks per occasion) and marijuana (no more than once per week), as well as consumption of beverages containing caffeine (unlimited) were permitted. Urine toxicology screening for opiates, cocaine, marijuana, and amphetamines was conducted before admission to the study, and was used to exclude subjects who presented evidence of recent use of cocaine or opiates.

Subjects were characterized as regular smokers if they reported smoking at least one pack of cigarettes per day, scored at least seven on the Fagerström Tolerance Questionnaire (Fagerström and Schneider, 1989), and showed afternoon expired air carbon monoxide values of at least $20 \mathrm{ppm}$. Self-reports of current and past drug use were obtained using a structured interview and the Addiction Severity Index (McLellan et al, 1980).

The National Institute of Mental Health Diagnostic Interview Schedule (DIS), modified for computerized selfadministration, was used to detect psychiatric disorders (Robins et al, 1981) using the criteria of the Diagnostic and Statistical Manual of Mental Disorders (DSM III) (American Psychiatric Association Committee on Nomenclature and Statistics, 1980). No subjects met criteria for any Axis I or Axis II diagnoses other than nicotine dependence. A score of at least 18 on the Vocabulary subtest of the Shipley Institute of Living Scale was required (Zachary, 1986). All subjects received payment for their participation and gave written informed consent under the supervision of the Institutional Review Boards of Johns Hopkins Hospital and Johns Hopkins Bayview Medical Center, Baltimore, MD, which houses the Intramural Research Program (IRP), NIDA.

Six subjects (four smokers and two nonsmokers, all men) completed the study, which included two FDG PET scans for measurement of cerebral glucose metabolism. They resided at the IRP, NIDA overnight before each PET scan but completed the other parts of the study on a nonresidential basis. Nicotine (cigarettes) and caffeine (beverages) were permitted ad libitum except on study days. Subjects were required to abstain from alcohol for $48 \mathrm{~h}$ and from cigarettes from midnight the night before each study day. Urine drug screening and a breath test for 
alcohol use (Intoximeter II) were performed on each study day.

Before the first PET scan, each subject participated in three test sessions, one with placebo and two with nicotine ( 0.75 and $1.5 \mathrm{mg}$, intravenous, administered in ascending dose order). The goals of these sessions were to familiarize the subjects with some of the procedures and to identify subjects who had adverse reactions to nicotine, in order to exclude them from further study. These tests were completed 2-32 days before the first PET scan, and the two PET scans were separated by 3-23 days.

The subjects also received structural MRI scans to identify (for exclusion) any participant who had a frank structural abnormality and to obtain structural data for coregistration with the PET data. On a GE 1.5 T Signa scanner, a sagittal scout scan was acquired to define the AC-PC line $(\mathrm{TR}=500, \mathrm{TE}=11, \mathrm{FOV}=24 \mathrm{~cm}$, matrix $256 \times 192, \mathrm{NEX}=1$; slices $4 \mathrm{~mm}$ in thickness, interleaved). An axial double echo (T2/proton, density) scan was acquired for diagnostic review $(\mathrm{TR}=3000, \mathrm{TE}=34$ / $100, \mathrm{FOV}=24 \mathrm{~cm}$, matrix $256 \times 192, \mathrm{NEX}=1$; slices $5 \mathrm{~mm}$ thick, interleaved). A transaxial Spoiled Grass volumetric scan to include the entire brain was acquired for registration with PET data $(\mathrm{TR}=38, \mathrm{TE}=13, \mathrm{FOV}=24 \mathrm{~cm}$, flip angle $=45^{\circ}$, matrix $256 \times 256, \mathrm{NEX}=1 ; 124$ slices, each $1.5 \mathrm{~mm}$ thick).

Each subject was fitted with a molded plastic facemask to facilitate positioning in PET and magnetic resonance imaging (MRI) scanners. On the day of each PET scan, the subject received a standard nonketogenic, caffeine-free breakfast, and then did not eat for at least $4 \mathrm{~h}$ before injection of the radiotracer. A radial arterial catheter was inserted after the administration of local anesthetic $(0.5 \%$ lidocaine $\mathrm{HCl}$, subcutaneously). Catheters were placed in veins of both forearms. An intravenous infusion of $0.45 \% \mathrm{NaCl}$ was initiated in the arm opposite to the arterial catheter. From about $30 \mathrm{~min}$ before until $30 \mathrm{~min}$ after injection of FDG, subjects were blindfolded and wore headphones projecting white noise and a 'beep' prompt presented once per minute. The subject was instructed to report on a scale of $0-5$, how much he felt the effect of the injected substance (placebo or nicotine) at the sound of the beep.

Either $1.5 \mathrm{mg}$ nicotine or saline placebo was infused intravenously over $10 \mathrm{~s}$ beginning at the time of the FDG injection. Drug order was double blind and randomized, and four subjects (two smokers) received nicotine first. Vital signs were monitored during all studies. A set of questionnaires was administered about $60 \mathrm{~min}$ before and 30 min after injection of the FDG in order to monitor effects on mood and feeling state. It included Visual Analog Scales (VAS), with seven items that tested drug effects (drug strength, good effects, bad effects, drug liking, high feeling, desire to take the drug again, and energy). Also administered were the Profile of Mood Scales (POMS), and three subscales from the Addiction Research Center Inventory (ARCI): the Morphine Benzedrine Group (MBG) subscale, a measure of positive effects; the Pentobarbital Chlorpromazine Alcohol Group subscale, sensitive primarily to fatigue and sedation; and the Lysergic Acid Diethylamide subscale, a measure of disorientation (Haertzen, 1974).

PET data were collected using the FDG procedure (Phelps et al, 1979; Reivich et al, 1979). The radiotracer ( $\leqslant 5 \mathrm{mCi}$, $\leqslant 185 \mathrm{MBq}$ FDG) was administered as an intravenous bolus, followed by a $20-\mathrm{ml}$ saline flush. Arterial blood sampling followed a fixed schedule of decreasing frequency (about 30 samples, taken at $0.25,0.5,0.75,1,1.5,3,5$, and 10 min after the injection of FDG, and thereafter at 10-min intervals until the end of scanning). Metabolic rates were calculated using standard rate constants, a lumped constant of 0.42 , and an operational equation (Huang et al, 1980), with a model for analytic integration of the specific radioactivity in the arterial plasma during the measurement (Phillips et al, 1995).

Scanning began $45 \mathrm{~min}$ after FDG injection, using a NeuroECAT PET scanner (Computers Technology and Imaging, Knoxville, TN). PET scans consisted of four 15min acquisitions, starting $45 \mathrm{~min}$ postinjection, resulting in 12 transaxial slices (parallel to the inferior orbitometal plane) with $8 \mathrm{~mm}$ slice-to-slice spacing. Images were reconstructed with a high-resolution Shepp-Logan filter, providing resolution equivalent to the intrinsic resolution of the scanner ( $8 \mathrm{~mm}$ within plane and $15 \mathrm{~mm}$ axially). Attenuation correction was performed with an ellipse and assumed an attenuation coefficient of $\mu=0.088 / \mathrm{cm}$, measured for water on the NeuroECAT.

The resultant PET images and corresponding MRI images were transferred to the NIH IMAGE 1.55 program (Rasband, 1990). A standard template of regions of interest (ROI) was constructed with reference to an anatomical atlas (Damasio, 1995). The template, consisting of 52 circles (144 pixels each) and four ellipses (300 pixels each) that identify brain areas in eight of the $25 \mathrm{MRI}$ slices, is a modification of the one that had been used previously (Stapleton et al, 1995).

MRI and PET scans from each study were compared with the anatomical atlas to select those eight planes that best matched the planes in the reference set. ROIs were placed on the MRI slices, using the template, by a rater who was blind to drug treatment. The same rater outlined each MRI slice using a threshold-based algorithm with visual correction. MRI and PET images were coregistered using a modified version of the IMAGE 1.55 program (Rasband, 1990) on a Macintosh computer, and the ROIs were transferred automatically from the MRI to the PET image. Global metabolic rate for glucose also was estimated as the mean (area weighted average) of all ROIs for each subject.

All data (rCMRglc and behavioral measures) were analyzed using SPSS-PC (SPSS, Inc., Chicago, IL) by analysis of variance (ANOVA). The criterion for statistical significance was set at $p<0.05$, without correction for the number of comparisons.

\section{Subjective Self-Reports}

Each variable derived from subjective self-reports was analyzed in an ANOVA with factors of Drug (placebo or nicotine) and Time (pre- or postinjection). Responses to the beep prompt ('How much do you feel the drug?') were averaged over 5 -min periods and analyzed in an ANOVA with factors of Drug (placebo or nicotine) and Time (six 5min periods). The Greenhouse-Geisser correction for repeated measures was used as appropriate for the 
subjective self-report data that included time as a dimension.

\section{Cerebral Glucose Metabolism}

Data for each ROI were analyzed by two-way ANOVA with factors of Drug (placebo or nicotine) and Laterality (left or right). The Laterality factor was omitted for midline individual ROIs. Comparisons of two means only were made using paired-sample $t$-tests.

\section{RESULTS}

\section{Cerebral Metabolism}

Compared with the placebo condition, cerebral metabolic rates were lower after nicotine injection (Table 1). When the area-weighted average of all ROIs (including midline structures) was used to estimate global metabolic rate, the estimate after nicotine was significantly lower, $p<0.05$ (by $9.51 \%)$, than after placebo $(7.61 \pm 1.04$ vs $8.41 \pm 1.36 \mathrm{mg} /$ $100 \mathrm{~g} / \mathrm{min}$ ). Assessments of individual ROIs indicated that nicotine reduced rCMRglc in each region sampled except the medial thalamus.

Although each region was tested separately, these effects cannot be separated from the global effect of nicotine. Nonetheless, this exploratory assessment indicated main effects of Drug in the superior frontal gyrus $(\mathrm{F}(1,5)=11.32$, $p=0.047)$, inferior frontal gyrus $(\mathrm{F}(1,5)=9.56, p=0.011)$, anterior cingulate gyrus $(\mathrm{F}(1,5)=10.91, p=0.021)$, insula $(\mathrm{F}(1,5)=17.38, \quad p=0.009), \quad$ parahippocampal gyrus $(\mathrm{F}(1,5)=16.39, p=0.010)$, cuneate sulcus $(\mathrm{F}(1,5)=8.88$, $p=0.031)$, caudate nucleus $(\mathrm{F}(1,5)=9.70, p=0.026)$, putamen $(\mathrm{F}(1,5)=19.57, \quad p=0.007)$, and cerebellar cortex $(\mathrm{F}(1,5)=8.29, p=0.035)$. These differences in rCMRglc, seen in laterally sampled (not midline) regions, ranged from 4.6 to $15.6 \%$.

Main effects of Laterality were found for insula $(\mathrm{F}(1,5)=9.29, p=0.028)$ and cuneate sulcus $(\mathrm{F}(1,5)=7.64$, $p=0.040$ ), with rCMRglc higher on the right than on the left, and for caudate nucleus $(\mathrm{F}(1,5)=8.96, p=0.030)$, with rCMRglc higher on the left than on the right. An interaction of Drug $\times$ Laterality was found for superior parietal gyrus $(\mathrm{F}(1,5)=7.55, p=0.040)$, with a greater decrease due to nicotine on the left than on the right.

Reanalysis of all data excluding the two nonsmokers generally showed similar results in terms of percentage decrease under nicotine although the variance was slightly smaller. In the smokers, the change in global metabolism $(8.06 \pm 0.87 \mathrm{mg} / 100 \mathrm{~g} / \mathrm{min}$ in the placebo condition vs $8.85 \pm 1.26 \mathrm{mg} / 100 \mathrm{~g} / \mathrm{min}$ after nicotine, $-8.93 \%)$ was slightly smaller $(p>0.05)$. Effects in most individual regions were of similar magnitude as when the nonsmokers were included, and the dispersion (ie SD) most often was smaller, but fewer regions showed significant differences because of the lower power. For example, in the smokers $(n=4)$, values in the superior frontal gyrus were $9.93 \pm 1.92$ (left) and $9.15 \pm 1.57$ (right) under placebo $v s 8.73 \pm 0.76$ (left) and $7.44 \pm 0.74$ (right) under nicotine (change of $15.2 \%)$. Values in the anterior cingulate gyrus were $9.86 \pm 0.59$ (left) and $9.99 \pm 1.72$ (right) under placebo $v s$ $8.02 \pm 0.36$ (left) and $8.37 \pm 0.74$ (right) under nicotine (change of $17.4 \%$ ).

\section{Mood Effects}

Self-reports of mood and drug-related feeling states demonstrated several effects induced by nicotine (Table 2). We first used the POMS to test two general hypotheses about mood effects. Nicotine had no significant effect on overall energy level as demonstrated by assessment of the Fatigue and Vigor scales (both $p$ 's $>0.05$ ). In contrast, significant Drug $\times$ Time interactions suggested that nicotine but not placebo increased negative emotion on three of four scales (Tension/Anxiety $(\mathrm{F}(1,5)=9.80, p=0.026)$, Depression $(\mathrm{F}(1,5)=6.83, \quad p=0.047)$, and Confusion scale $(\mathrm{F}(1,5)=11.14, p=0.021)$, but not Anger, $p>0.05)$.

\section{Drug Feelings}

Analysis of responses to the beep prompt ('How much do you feel the drug?') yielded a statistically significant Drug $\times$ Time interaction $\quad(\mathrm{F}(1,17)=23.65, \quad p<0.001)$, indicating that nicotine produced a greater effect than placebo, and that the effect diminished over time after the first $5 \mathrm{~min}$ following the drug injection. When data from the two nonsmokers were excluded, the data showed less variability but otherwise were similar (responses of $2.25 \pm 0.50$ and $2.05 \pm 1.06$ at $1-5$ and $6-10 \mathrm{~min}$, respectively).

Analysis of responses to the beep prompt ('How much do you feel the drug?') yielded a statistically significant Drug $\times$ Time interaction $(\mathrm{F}(1,17)=23.65, p<.001)$, indicating that nicotine did produce a greater drug feeling than placebo, and that the effect diminished over time after the first $5 \mathrm{~min}$ following injection. When data from the two nonsmokers were excluded, the data showed less variability but otherwise were similar (responses of $2.25 \pm 0.50$ and $2.05 \pm 1.06$ at $1-5$ and $6-10 \mathrm{~min}$, respectively).

There were no statistically significant effects or interactions on any of the ARCI subscales, suggesting nicotineinduced feelings did not resemble feelings induced by opiates, depressants, or psychedelics.

VAS responses were consistent with the results reported above for both mood and drug feelings. As with the Fatigue and Vigor POMS scales, the 'Energetic' VAS showed no evidence that nicotine affected overall energy level $(p>0.05)$. As with responses to the beep prompt, there was clear evidence that nicotine induced drug feelings, as indicated by statistically significant Drug $\times$ Time interactions for the VAS questions, 'How strong was the drug?' $(\mathrm{F}(1,5)=76.97, p<0.001)$ and 'How high did it make you feel?' $(\mathrm{F}(1,5)=37.40, p=0.002)$. In line with the POMS tests of negative effect, VAS results suggested that intravenous nicotine induced primarily negative affect, with significant results for "How much did the drug have bad effects?' $(\mathrm{F}(1,5)=13.37, p=0.015)$, but not for 'Good Effects', 'Like the Drug', or 'Want to Take the Drug Again' (all $p$ 's $>0.05$ ). However, when analysis was restricted to the four smokers, mean responses on all six measures other than the 'bad effects' scale were higher after nicotine, and the variance was smaller. This indicates that nonsmokers reported weaker positive effects than did smokers (strong: $93.3 \pm 4.8$; good: $38.8 \pm 34.6$; like: $23.5 \pm 39.8$; high: $89.0 \pm 10.2$; take again: $27.5 \pm 43.6$; energetic: $65.8 \pm 39.2$ ). 
Table I Effects of Nicotine on Regional Cerebral Glucose Metabolism

\begin{tabular}{|c|c|c|c|c|c|}
\hline \multirow[b]{2}{*}{$\Delta \%$} & \multicolumn{2}{|c|}{ Placebo } & \multicolumn{2}{|c|}{ Nicotine } & \\
\hline & Left & Right & Left & Right & \\
\hline \multicolumn{6}{|l|}{ Frontal neocortex } \\
\hline $\begin{array}{l}\text { Superior frontal G. } \\
\text { Middle frontal G. } \\
\text { Inferior frontal G. } \\
\text { Precentral G. }\end{array}$ & $\begin{array}{r}9.17(2.07) \\
9.87(1.84) \\
9.80(2.10) \\
10.56(1.60)\end{array}$ & $\begin{array}{r}9.15(1.57) \\
10.64(1.88) \\
9.66(1.61) \\
10.47(1.74)\end{array}$ & $\begin{array}{l}7.77(1.60) \\
9.09(1.78) \\
8.39(1.56) \\
9.20(1.50)\end{array}$ & $\begin{array}{l}7.38(1.00) \\
9.61(1.45) \\
8.55(1.39) \\
9.31(1.30)\end{array}$ & $\begin{array}{l}-\mathbf{1 5 . 4} \\
-8.82 \\
-\mathbf{1 3 . 0} \\
-12.0\end{array}$ \\
\hline \multicolumn{6}{|l|}{ Frontal limbic } \\
\hline $\begin{array}{l}\text { Orbitofrontal cortex } \\
\text { Anterior cingulate } \\
\text { Gyrus rectus }\end{array}$ & $\begin{array}{l}8.81(1.29) \\
9.65(1.32) \\
8.40(1.38)\end{array}$ & $\begin{array}{l}8.62(1.96) \\
9.59(1.71) \\
7.82(1.68)\end{array}$ & $\begin{array}{l}8.46(1.56) \\
8.11(0.83) \\
7.43(1.03)\end{array}$ & $\begin{array}{l}8.17(1.67) \\
8.11(0.70) \\
7.38(0.85)\end{array}$ & $\begin{array}{c}-4.60 \\
-\mathbf{I 5 . 6} \\
-8.69\end{array}$ \\
\hline \multicolumn{6}{|l|}{ Temporal neocortex } \\
\hline $\begin{array}{l}\text { Temporal pole } \\
\text { Superior temporal G. } \\
\text { Middle temporal G. } \\
\text { Inferior temporal G. } \\
\text { Insula D, L }\end{array}$ & $\begin{array}{l}5.50(1.60) \\
7.28(1.89) \\
8.85(1.51) \\
8.14(1.20) \\
8.45(1.39)\end{array}$ & $\begin{array}{l}5.81(1.50) \\
7.72(1.50) \\
9.31(1.76) \\
8.77(1.52) \\
9.53(1.94)\end{array}$ & $\begin{array}{l}5.27(1.05) \\
6.63(1.66) \\
8.07(1.56) \\
7.53(1.65) \\
7.97(1.09)\end{array}$ & $\begin{array}{l}5.32(1.11) \\
6.86(1.32) \\
8.52(1.49) \\
7.63(1.13) \\
8.95(1.78)\end{array}$ & $\begin{array}{c}-6.37 \\
-10.1 \\
-8.65 \\
-10.4 \\
-\mathbf{5 . 9 0}\end{array}$ \\
\hline \multicolumn{6}{|l|}{ Medial temporal lobe } \\
\hline $\begin{array}{l}\text { Parahippocampal G. } \\
\text { Hippocampus } \\
\text { Amygdala }\end{array}$ & $\begin{array}{l}7.38(1.33) \\
5.76(1.32) \\
5.31(1.58)\end{array}$ & $\begin{array}{l}7.32(1.25) \\
6.06(1.34) \\
5.50(0.83)\end{array}$ & $\begin{array}{l}6.22(1.06) \\
5.14(0.96) \\
4.90(0.90)\end{array}$ & $\begin{array}{l}6.48(0.94) \\
5.34(0.98) \\
4.85(0.59)\end{array}$ & $\begin{array}{l}-13.6 \\
-11.3 \\
-9.72\end{array}$ \\
\hline \multicolumn{6}{|l|}{ Parietal cortex } \\
\hline $\begin{array}{l}\text { Superior parietal G.DL } \\
\text { Postcentral gyrus } \\
\text { Paracentral lobule } \\
\text { Precuneus }\end{array}$ & $\begin{array}{r}8.84(1.79) \\
8.50(1.81) \\
8.01(1.39) \\
10.13(2.82)\end{array}$ & $\begin{array}{r}9.36(1.49) \\
8.56(1.88) \\
8.06(1.92) \\
10.37(2.00)\end{array}$ & $\begin{array}{l}8.10(1.46) \\
7.72(1.15) \\
7.47(1.23) \\
9.74(2.20)\end{array}$ & $\begin{array}{l}8.95(1.07) \\
7.41(1.59) \\
7.33(2.05) \\
9.69(1.88)\end{array}$ & $\begin{array}{l}-6.32 \\
-11.3 \\
-7.90 \\
-5.22\end{array}$ \\
\hline \multicolumn{6}{|l|}{ Occipital cortex } \\
\hline $\begin{array}{l}\text { Calcarine cortex } \\
\text { Lateral occipital G. } \\
\text { Cuneus } \mathrm{D}, \mathrm{L}\end{array}$ & $\begin{array}{r}10.11(1.42) \\
7.16(2.08) \\
9.31(1.94)\end{array}$ & $\begin{array}{r}10.21(2.01) \\
7.45(2.36) \\
10.39(2.12)\end{array}$ & $\begin{array}{l}9.65(0.97) \\
6.06(1.36) \\
8.57(1.29)\end{array}$ & $\begin{array}{l}9.61(1.60) \\
6.40(1.82) \\
9.05(1.25)\end{array}$ & $\begin{array}{l}-5.22 \\
-14.7 \\
-\mathbf{I 0 . 6}\end{array}$ \\
\hline \multicolumn{6}{|l|}{ Basal ganglia/thalamus } \\
\hline $\begin{array}{l}\text { Caudate nucleus }{ }^{\mathrm{D}, ~} \mathrm{~L} \\
\text { Putamen }^{\mathrm{D}} \\
\text { Thalamus }\end{array}$ & $\begin{array}{r}10.11(1.42) \\
9.57(1.45) \\
8.57(1.29)\end{array}$ & $\begin{array}{l}8.85(1.53) \\
9.95(1.65) \\
8.40(1.36)\end{array}$ & $\begin{array}{l}9.65(0.97) \\
8.49(1.25) \\
7.77(0.87)\end{array}$ & $\begin{array}{l}8.64(1.19) \\
8.91(1.17) \\
7.74(1.32)\end{array}$ & $\begin{array}{c}-\mathbf{5 . 2 1} \\
-\mathbf{1 0 . 9} \\
-8.60\end{array}$ \\
\hline \multicolumn{6}{|l|}{ Cerebellum } \\
\hline $\begin{array}{l}\text { Cerebellar Cortex } \\
\text { Midline regions }\end{array}$ & $8.24(1.64)$ & $8.16(1.63)$ & $7.73(1.01)$ & $7.07(0.96)$ & -14.0 \\
\hline $\begin{array}{l}\text { Thalamus } \\
\text { Midbrain } \\
\text { Cerebellar vermis } \\
\text { Pons }\end{array}$ & $\begin{array}{l}7.34(1.55) \\
6.13(0.90) \\
6.92(1.21) \\
5.33(0.75)\end{array}$ & & $\begin{array}{l}7.56(1.39) \\
5.94(0.79) \\
5.87(1.02) \\
4.90(0.99)\end{array}$ & $\begin{array}{c}+3.00 \\
-3.10 \\
-15.2 \\
-8.07\end{array}$ & \\
\hline
\end{tabular}

Mean $( \pm \mathrm{SD}$ ) regional cerebral metabolic rate for glucose ( $\mathrm{rCMRglc}, \mathrm{mg} / \mathrm{l} 00 \mathrm{~g} / \mathrm{min}$ ); $n=6$ (four smokers, two nonsmokers). $D=$ Drug factor, nicotine different from placebo; $L=$ laterality factor, left different from right; $\mathrm{DL}=$ Drug $\times$ Laterality interaction, $p$ 's $<0.05$ by two-way ANOVA (bilateral regions), with drug treatment (placebo, nicotine) and hemisphere as the factors. Tests of midline regions were performed by Student's t-test (one-tailed). There was no correction for multiple comparisons (number of brain regions).

\section{DISCUSSION}

This study demonstrates that $1.5 \mathrm{mg}$ nicotine administered intravenously reduced global glucose metabolism. This nicotine-induced decrease is consistent with results obtained with nicotine nasal spray (Domino et al, 2000) although the effect here was greater in magnitude. The difference may reflect characteristics of the routes of administration. 
Table 2 Effects of Intravenous Nicotine on Subjective Self-Reports ${ }^{a}$

\begin{tabular}{|c|c|c|c|c|}
\hline & \multicolumn{2}{|c|}{ Placebo } & \multicolumn{2}{|c|}{ Nicotine } \\
\hline & Pre & Post & Pre & Post \\
\hline \multicolumn{5}{|l|}{ Profile of mood states } \\
\hline $\begin{array}{l}\text { Tension }{ }^{\mathrm{D}, \mathrm{DT}} \\
\text { Depression }^{\mathrm{DT}} \\
\text { Anger } \\
\text { Vigor } \\
\text { Fatigue } \\
\text { Confusion }\end{array}$ & $\begin{array}{l}5.7 \pm 3.4 \\
0.3 \pm 0.5 \\
0.2 \pm 0.4 \\
8.3 \pm 1.9 \\
0.8 \pm 1.2 \\
2.8 \pm 1.5\end{array}$ & $\begin{array}{l}6.7 \pm 5.8 \\
0.3 \pm 0.8 \\
0.0 \pm 0.0 \\
6.2 \pm 1.8 \\
1.3 \pm 1.5 \\
2.7 \pm 1.2\end{array}$ & $\begin{array}{l}7.0 \pm 5.3 \\
0.8 \pm 1.3 \\
0.8 \pm 1.3 \\
8.2 \pm 3.1 \\
1.0 \pm 1.3 \\
3.8 \pm 1.7\end{array}$ & $\begin{array}{r}16.8 \pm 11.6 \\
10.7 \pm 10.4 \\
7.0 \pm 8.2 \\
6.5 \pm 6.6 \\
0.8 \pm 1.3 \\
10.7 \pm 5.8\end{array}$ \\
\hline \multicolumn{5}{|l|}{ Visual analogue scales } \\
\hline $\begin{array}{l}\text { Drug strength } \mathrm{D}, \mathrm{T}, \mathrm{DT} \\
\text { Good effects } \\
\text { Bad effects } \mathrm{D}, \mathrm{T}, \mathrm{DT} \\
\text { Like the drug } \\
\text { High } \mathrm{D} \text {, T, DT } \\
\text { Want to take the drug again } \\
\text { Energetic }\end{array}$ & $\begin{array}{l}0.0 \pm 0.0 \\
0.0 \pm 0.0 \\
0.0 \pm 0.0 \\
0.0 \pm 0.0 \\
0.0 \pm 0.0 \\
0.0 \pm 0.0 \\
0.0 \pm 0.0\end{array}$ & $\begin{array}{l}2.2 \pm 5.3 \\
0.0 \pm 0.0 \\
2.0 \pm 4.9 \\
0.0 \pm 0.0 \\
1.8 \pm 4.5 \\
0.0 \pm 0.0 \\
0.0 \pm 0.0\end{array}$ & $\begin{array}{l}0.0 \pm 0.0 \\
0.0 \pm 0.0 \\
0.0 \pm 0.0 \\
0.0 \pm 0.0 \\
0.0 \pm 0.0 \\
0.0 \pm 0.0 \\
0.0 \pm 0.0\end{array}$ & $\begin{array}{l}81.7 \pm 18.3 \\
28.0 \pm 31.8 \\
54.7 \pm 35.3 \\
18.3 \pm 32.3 \\
73.0 \pm 26.4 \\
17.3 \pm 35.0 \\
45.7 \pm 43.6\end{array}$ \\
\hline \multicolumn{5}{|l|}{ Addiction research center inventory } \\
\hline $\begin{array}{l}\text { Morphine Benzedrine Group } \\
\text { Phenobarbital-Chlorpromazine Alcohol Group } \\
\text { LSD }\end{array}$ & $\begin{array}{l}1.7 \pm 1.9 \\
4.7 \pm 1.4 \\
4.7 \pm 1.4\end{array}$ & $\begin{array}{l}2.0 \pm 0.6 \\
4.5 \pm 2.8 \\
4.6 \pm 2.8\end{array}$ & $\begin{array}{l}1.3 \pm 0.8 \\
5.0 \pm 1.7 \\
4.7 \pm 2.1\end{array}$ & $\begin{array}{l}1.5 \pm 1.4 \\
6.5 \pm 4.1 \\
8.2 \pm 2.9\end{array}$ \\
\hline \multicolumn{5}{|l|}{ Responses to beep prompts ${ }^{\mathrm{b}} \mathrm{D}, \mathrm{T}, \mathrm{DT}$} \\
\hline $\begin{array}{l}1-5 \mathrm{~min} \text { postinjection } \\
6-10 \mathrm{~min} \text { postinjection } \\
\text { I I-15 min postinjection } \\
16-20 \mathrm{~min} \text { postinjection } \\
21-25 \mathrm{~min} \text { postinjection } \\
26-30 \mathrm{~min} \text { postinjection }\end{array}$ & $\begin{array}{c}0.13 \pm 0.33 \\
0 \\
0 \\
0 \\
0 \\
0\end{array}$ & & $\begin{array}{l}2.83 \pm 0.85 \\
1.13 \pm 1.14 \\
0.17 \pm 0.41 \\
0.10 \pm 0.24 \\
0 \\
0\end{array}$ & \\
\hline
\end{tabular}

${ }^{a}$ Each value is the mean $\pm S D$ for $n=6$ (four smokers+two nonsmokers). ${ }^{b}$ Subjects responded to prompts presented every minute, and reported how much they felt the effect of the injected substance (placebo or nicotine) on a scale of 0 (no effect) to 5 (extremely). $D=$ Drug factor, placebo different from nicotine, $p<0.05$. $T=$ Time factor, pre-different from postinjection, $p<0.05$ (difference across time points, $p<0.05$ ). DT $=$ Drug $\times$ Time interaction $\mathrm{P}<0.05$

Brain regions that showed large nicotine-induced increases of rCMRglc in the rat (London et al, 1985a, 1988a b; Grünwald et al, 1987, 1988) were spared from metabolic decrements in this human study. These regions were midline structures (medial thalamus, midbrain, and cerebellar vermis). One explanation is that rCMRglc reflects the sum of simultaneous processes, and that regional increases of rCMRglc (seen in rat studies) are balanced by a decrement in global metabolism of the human brain (not observed in the rat). This explanation may be relevant to the relative activation of the thalamus that accompanied a nonsignificant decrease in global glucose metabolism after administration of nicotine nasal spray (Domino et al, 2000). Indeed, against the background of reduced global metabolism seen here, relative activity in the thalamus is increased by intravenous nicotine as well (see Table 1).

Although inconsistent with the localized rCMRglc increases in rats, widespread deactivation in humans, as seen here, has also been demonstrated in response to cocaine and other drugs of abuse (London et al, 1996). In fact, nicotine resembles most drugs of abuse, by reducing cerebral metabolism. These results contribute to the growing evidence that, in spite of its legal status, nicotine shares characteristic effects on brain function with prototypic drugs of abuse, such as cocaine.

As smokers in this study abstained from smoking for about $12 \mathrm{~h}$, we considered the influence of withdrawal on the findings. Nicotine withdrawal is characterized by decreased arousal, with slowing of the electroencephalogram, reduced evoked potential amplitude, decreased heart rate, and subjective reports of drowsiness (Hughes et al, 1990). If decreased cortical arousal were to accompany decreased rCMRglc, acute nicotine administration would presumably increase rCMRglc. In contrast, rCMRglc decreased after acute nicotine administration. The data showing a similar decrease in rCMRglc in two nonsmokers also argues against a major role of nicotine withdrawal in this study.

The results of this study contrast with reports of nicotineinduced increase in activity in frontal, temporal and occipital structures using fMRI (Stein et al, 1998) and assays of regional CBF (Nagata et al, 1995; Rose et al, 1998; Zubieta et al, 2001). These discrepancies across studies may 
be because of differences in the relations between neuronal activity and the actual dependent measures (Barinaga, 1997), which were glucose utilization (current study), CBF (Ghatan et al, 1998), and blood oxygenation levels (Stein et al, 1998). An important variable may be the time course of the dependent measures (eg the FDG uptake period ( $30 \mathrm{~min})$ is long relative to the subjective nicotine effect). While the mechanism for the nicotine-induced reduction of glucose metabolism is not known, experimental data point to a role of astrocytes in coupling the activity of glutamate released by active neurons to cerebral glucose metabolism (Magistretti and Pellerin, 1996). Thus, the observed actions of nicotine in human brain may reflect an inhibition of glutamate release.

\section{ACKNOWLEDGEMENTS}

We thank Drs W Robert Lange and Carlo Contoreggi for medical coverage; Merrily Smith, RN and Robin Stauffer, $\mathrm{RN}$ for nursing services; Valerie O'Brien and Jennifer Schmidt for help with data collection and analysis; and David Clough, CNMT and William Smoot, CNMT for PET data acquisition.

\section{REFERENCES}

American Psychiatric Association Committee on Nomenclature and Statistics (1980). Diagnostic and Statistical Manual of Mental Disorders. American Psychiatric Association: Washington, DC.

Barinaga M (1997). What makes brain neurons run? Science 276: 196-198.

Boyajian RA, Otis S (2000). Acute effects of smoking on human cerebral blood flow: a transcranial Doppler ultrasonography study. J Neuroimaging 10: 204-208.

Clarke PBS, Pert C, Pert A (1984). Autoradiographic distribution of nicotine receptors in rat brain. Brain Res 323: 390-395.

Damasio H (1995). Human Brain Anatomy in Computerized Images. Oxford University Press: New York.

Domino EF, Minoshima S, Guthrie SK, Ohl L, Ni L, Koeppe RA et al (2000). Effects of nicotine on regional cerebral glucose metabolism in awake resting tobacco smokers. Neuroscience 101: 277-282.

Fagerström KO, Schneider NG (1989). Measuring nicotine dependence: a review of the Fagerström tolerance questionnaire. J Behav Med 12: 159-182.

Ghatan PH, Ingvar M, Erikson L, Stone-Elander S, Serrander M, Ekberg K et al (1998). Cerebral effects of nicotine during cognition in smokers and non-smokers. Psychopharmacology (Berl) 136: 179-189.

Grünwald F, Schröck H, Kuschinsky W (1987). The effect of an acute nicotine infusion on the local cerebral glucose utilization of the awake rat. Brain Res 400: 232-238.

Grünwald F, Schröck H, Theilen H, Biber A, Kuschinsky W (1988). Local cerebral glucose utilization of the awake rat during chronic administration of nicotine. Brain Res 456: 350-356.

Haertzen CA (1974). An overview of Addiction Research Center Inventory Scales (ARCI): an appendix and manual of scales. Department of Health Education and Welfare Publication No. (ADM) 74-92, NIDA, Rockville.

Henningfield JE, Miyasato K, Jasinski DR (1985). Abuse liability and pharmacodynamic characteristics of intravenous and inhaled nicotine. J Pharmacol Exp Ther 234: 1-12.
Henningfield JE, Stapleton JM, Benowitz NL, London ED (1993). Higher levels of nicotine in arterial than in venous blood after cigarette smoking. Drug Alcohol Depend 33: 23-29.

Huang S-C, Phelps ME, Hoffman EJ, Sideris K, Selin CJ, Kuhl DE (1980). Noninvasive determination of local cerebral metabolic rate of glucose in man. Am J Physiol 238: E69-E82.

Hughes JR, Higgins ST, Hatsukami D (1990). Effects of abstinence from tobacco: a critical review. In: Kozlowski LT, Annis HM, Cappell HD, Glaser FB, Goodstadt MS, Israel Y, Kalant H, Sellers EM, Vingilis ER (eds). Research Advances in Alcohol and Drug Problems, Vol. 10, Plenum Press: New York. pp 317-398.

Jones HE, Garret BE, Griffiths RR (1999). Subjective and physiological effects of intravenous nicotine and cocaine in cigarette smoking cocaine abusers. J Pharmacol Exp Ther 288: 188-197.

London ED, Connolly RJ, Szikszay M, Wamsley JK (1985a). Distribution of cerebral metabolic effects of nicotine in the rat. Eur J Pharmacol 110: 391-392.

London ED, Connolly RJ, Szikszay M, Wamsley JK, Dam M (1988a). Effects of nicotine on local cerebral glucose utilization in the rat. J Neurosci 8: 3920-3928.

London ED, Dam M, Fanelli RJ (1988b). Nicotine enhances cerebral glucose utilization in central components of the rat visual system. Brain Res Bull 20: 381-385.

London ED, Grant SJ, Morgan MJ, Zukin SR (1996). Neurobiology of drug abuse. In: Fogel BS, Schiffer RB, Rao SM (eds). Neuropsychiatry. Williams \& Wilkins: Baltimore, MD. pp 635678.

London ED, Waller SB, Wamsley JK (1985b). Autoradiographic localization of $\left[{ }^{3} \mathrm{H}\right]$ nicotine binding sites in the rat brain. Neurosci Lett 53: 179-184.

Lukas RJ (1998). Neuronal nicotinic acetylcholine receptors. In: Barrantes F (ed). The Nicotinic Acetylcholine Receptor: Current Views and Future Trends. Springer: Berlin, New York. pp 145173.

Magistretti PJ, Pellerin L (1996). The contribution of astrocytes to the 18F-2-deoxyglucose signal in PET activation studies. $\mathrm{Mol}$ Psychiatry 1: 445-452.

McLellan AT, Luborsky L, Woody GE, O'Brien CP (1980). An improved evaluation instrument for substance abuse patients: The Addiction Severity Index. J Nerv Ment Dis 168: 26-33.

McNamara D, Larson DM, Rapoport SI, Soncrant TT (1990). Preferential metabolic activation of subcortical brain areas by acute administration of nicotine to rats. J Cereb Blood Flow Metab 10: 48-56.

Nagata K, Shinohara T, Kanno I, Hatazawa J, Domino E (1995). Effects of tobacco cigarette smoking on cerebral blood flow in normal adults. In: Domino EF (ed). Brain Imaging of Nicotine and Tobacco Smoking. NPP Books: Ann Arbor. pp 95-107.

Phelps ME, Huang SC, Hoffman EJ, Selin C, Sokoloff L, Kuhl DE (1979). Tomographic measurement of local cerebral glucose metabolic rate in humans with (F-18)2-fluoro-2-deoxy-D-glucose: validation of method. Ann Neurol 6: 371-388.

Phillips RL, Chen CY, Wong DF, London ED (1995). An improved method to calculate metabolic rates for glucose using PET. J Nucl Med 36: 1668-1679.

Pontieri FE, Gianluigi T, Orzi F, Di Chiara G (1996). Effects of nicotine on the nucleus accumbens and similarity to those of addictive drugs. Nature 382: 255-257.

Rasband WS (1990). Image: Image Processing and Analysis. National Institute of Health, Research Services Branch: Rockville.

Reivich M, Kuhl D, Wolf A, Greenberg J, Phelps M, Ido T et al (1979). The $\left[{ }^{18} \mathrm{~F}\right]$ fluorodeoxyglucose method for the measurement of local cerebral glucose utilization in man. Circ Res 44: 127-137. 
Robins LN, Helzer JE, Croughan J, Ratcliff KS (1981). National Institute of Mental Health Diagnostic Interview Schedule: its history, characteristics, and validity. Arch Gen Psychiatry 38: 381-389.

Rose JE, Behm FM, Westman EC, Johnson MP, Bates JE, Mathew $\mathrm{RJ}$ et al (1998). Acute effects of nicotine on regional and global cerebral blood flow (Abstract). Society Research on Nicotine and Tobacco, Symposium Brain Imaging of Nicotine and Tobacco Smoking; March 27-29; New Orleans, LA.

Sokoloff L, Reivich M, Kennedy C, Des Rosiers MH, Patlak CS, Pettigrew KD et al (1977). The $\left[{ }^{14} \mathrm{C}\right]$ deoxyglucose method for the measurement of local cerebral glucose utilization: theory, procedure, and normal values in the conscious and anesthetized albino rat. J Neurochem 28: 897-916.

Soria R, Stapleton JM, Gilson SF, Sampson-Cone A, Henningfield JE, London ED (1996). Subjective and cardiovascular effects of

nicotine in human volunteers. Psychopharmacology (Berl) 128: 221-226.

Stapleton J, London ED (1995). Imaging techniques. In: Jaffe JH (ed). Encyclopedia of Drugs of Alcohol, pp 573-576.

Stapleton JM, Morgan MJ, Phillips RL, Wong DF, Young BCK, Shaya EK et al (1995). Cerebral glucose utilization in polysubstance abuse. Neuropsychopharmacology 13: 21-31.

Stein EA, Pankiewicz J, Harsch HH, Cho JK, Fuller SA, Hoffmann RG et al (1998). Nicotine-induced limbic cortical activation in the human brain: a functional MRI study. Am J Psychiatry 155: 1009-1015.

Zachary RA (1986). Shipley Institute of Living Scale. Western Psychological Services: Los Angeles.

Zubieta JK, Lombardi U, Minoshima S, Guthrie S, Li Song N, Ohl LE et al (2001). Regional cerebral blood flow effects of nicotine in overnight abstinent smokers. Biol Psychiatry 49: 906-913. 